\title{
Por el artevida del pueblo: Debates en torno al folclore en Chile. 1973-19901
}

\section{For the Sake of Art and Life the People: Debates about Folklore in Chile, 1973-1990}

\author{
por \\ Karen Donoso Fritz \\ Universidad de Santiago de Chile, Chile \\ kdonoso@gmail.com \\ "El folclore es mucho más que cantos y danzas, es una forma de vida del pueblo... \\ Una proyección sin ese compromiso de una verdadera defen sa de los \\ valores culturales es un trabajo artístico paternalista, cómodo y flojo, y carece \\ de validez porque le falta la relación con el hombrey su medio ambiente... "
}

(Boletín AM FOLCHI, 1985)

El presente escrito indaga en el debate producido entre dos grandes líneas interpretativas sobre el folclore, definido ya sea como patrimonio nacional o comprendido como formas expresivas de la cultura popular. En el periodo 1973-1989 se produjo la imposición de la mirada "nacionalista", producto de las políticas culturales del régimen militar y la "batalla del folclore" fue dada por quienes se han acercado a este concepto a partir de la búsqueda y difusión del folclore como "arte-vida" popular.

Palabras clave: folclore, nacionalismo, cultura popular, políticas culturales.

During the 20th century folklore research followed two broad lines of interpretation. One of them considers folklore as a national patrimony. The other line considers folklore as a form of expression of popular culture. This article deals with the debate arising among the followers of these two lines. In the period comprised between theyears 1973 1989 the "nationalist" outlook was imposed in Chile as part of the cultural policies of the military government. It was then that the "battle of folklore" was fought by those for whom this concept was linked with the study and diffusion of folklore as the popular form of relation ship between art and life.

Keywords folklore, nationalist, popular culture, cultural politics.

\section{LAS POLÉMICAS DEL FOLCLORE}

En la edición de los Anales de la Universidad de Chile de agosto de 1911 apareció inserto un artículo titulado "Adivinanzas corrientes en Chile" del investigador

\footnotetext{
${ }^{1}$ Este artículo es producto de la investigación para la tesis de grado La batalla del folclore: los conflictos por la representación dela cultura popular en Chile, defendida en septiembre de 2006 en la Universidad de Santiago de Chile. Le agradezco a Verónica Valdivia y Maximiliano Salinas sus comentarios.
} 
Eliodoro Flores, miembro de la Sociedad del Folklore Chileno (SFCh). Como estaba acordado, los artículos que se discutían en dicha Sociedad serían publicados en la R evista del Folklore Chileno y en los Anales, órgano científico y oficial de la Universidad. El autor, profesor del Instituto Nacional, realizó una recopilación de adivinanzas entre el pueblo y, para provocar expectación entre los lectores, acordó con Rodolfo Lenz (presidente de la SFCh) no entregar las respuestas a las adivinanzas sino hasta la publicación de la segunda parte, el semestre que le siguió. A partir de este hecho se produjo una encarnada polémica que se manifestó en la prensa. El Diario Ilustrado publicó, en primera plana, que dicho artículo era,

"torpe, grosero, repugnante, nauseabundo, es un atentado contra la moral, un insulto contra la cultura nacional, una afrenta vergonzosa para la Universidad", en tanto que en su símil porteño La Unión se explica que "hemos visto una abundante colección de indecencias tan inmundas, tan asquerosas, tan repugnantes y tan burdas, que no es posible siquiera insinuar en qué consisten. So pretexto de las adivinanzas, se estampan en letra de molde [...] todo lo que constituye la delicia de los bajos fondos sociales, lo más grosero que pueda discurrir la malicia y la ignorancia populares, esos acertijos de doble sentido cuya miga está en su estructura brutalmente torpe, ya que las soluciones resultan totalmente imbéciles"2.

Las adivinanzas a que se hace referencia decían: "Pica con el piquito/tira con el potito; Un ave que no tiene pechos y cría/ a los vivos da la vida y a los muertos la alegría; Un animalito lacre/ que pica y no saca sangre; Meto lo duro en lo blando/ y las dos quedan colgando" ${ }^{3}$. Se cuestionaron también dos adivinanzas que Eliodoro Flores entregó como ejemplo y que aludían a políticos como Ventura Blanco Viel y Pedro Montt. Este hecho significó que la publicación de la segunda parte de las adivinanzas fuera cancelada, a la vez que Domingo Amunátegui (Rector de la Universidad de Chile) le advirtió a Rodolfo Lenz que tuviera más cuidado y cautela con lo que publicaban los miembros de su sociedad ${ }^{4}$.

La respuesta de Lenz y Eliodoro Flores buscaron explicar que las adivinanzas eran picarescas, que parecen aludir a actos "no muy finos", pero que su respuesta siempre era "inofensiva", aunque eso depende de la solución que busque cada cual. También plantearon como argumento que su objeto de estudio, el pueblo chileno, poseía la picardía como una característica importante de su idiosincrasia, por lo tanto, no podían censurar "ese lado del alma popular", pues "el coleccionador folclórico recoge no escoge los materiales" 5 .

EI Diario llustrado 1911: 1; La Unión 1911: 1.

${ }^{3}$ Flores 1911: 771-773. Las respuestas, aparecidas en el tomo siguiente de la Revista del Folclore Chileno son: la aguja, la abeja, el ají y los aros.

${ }^{4}$ Carta enviada por Domingo Amunátegui a Rodolfo Lenz, 22 de agosto de 1911. Archivo Rodolfo Lenz, UMCE. En ese entonces, Amunátegui (1860-1946) era rector de la Universidad de Chile. Las adivinanzas referidas a las "personas serias" son: Ninguna tien en los bu eyes/ y los toros tien en dos/ ninguna tien en las papas/ y una el Presidente M ontt", la respuesta es la letra $\mathrm{O}$; la otra adivinanza tiene como respuesta a Ventura Blanco Viel (VBV): "Te prometo bella Elena/ regalarte un par de tortas/ si me dices cuál convienel quépechoño tienel una larga entre dos cortas".

${ }^{5}$ El M ercurio 1911. 
Noventa años después, durante el acto de asunción del mando presidencial de Ricardo Lagos en la Estación Mapocho, se presentó la agrupación Los Chileneros, que cultivaba el género "cueca centrina”. Mientras los cantores entonaban las cuecas bravas, la pareja compuesta por Hiranio Chávez y Rita Núñez bailaron al más puro estilo de las casas de canto de los arrabales chilenos. Este hecho, presentado en un acto oficial y ante la presencia de delegaciones extranjeras, fue criticado por la parlamentaria de la Unión Demócrata Independiente (UDI) María Angélica Cristi, quien reclamó la participación de este grupo con el siguiente tenor: "[...] desde mi punto de vista, el acto no representó en nada a la música chilena. Apareció un conjunto de tres personas y una pareja de bailarines [...]. Se tocó música chilena y se bailaron tres pies de cueca. Tal presentación fue de muy mal gusto, porque no representaba en nada a quienes siempre han sido los más auténticos exponentes de la música chilena [...]. La gala de la Estación Mapocho fue hecha con mucho esfuerzo, y habiendo gran cantidad de conjuntos folclóricos con tanto prestigio no sólo en Chile, sino en el mundo, el que actuó hizo una presentación similar a lo que ofrece una tanguería, porque más bien parecía una pareja que bailaba tango en lugar de música chilena [...] ¿por qué teníamos que dar a todas estas visitas extranjeras la imagen de que esa pareja de bailarines con ese grupo de músicos eran representativos de nuestro folclore nacional?" 6 .

Ambos hechos nos llevan a una misma pregunta: ¿por qué cuando una expresión del folclore popular fue exhibida en espacios estatales, fue cuestionada por no pertenecer a la cultura nacional? ¿Qué pasó en nuestro país, que se repitió la misma discusión con noventa años de diferencia? En ambos casos, los cuestionamientos hacen referencia a lo inapropiado de ese tipo de demostración de la cultura chilena frente a los extranjeros, cuestionando la imagen país que se proyectaría: en el caso de los Anales, éste era el órgano de comunicación de la Universidad nacional con los centros científicos europeos; en el caso de las cuecas, éste era el acto de asunción de un Presidente de la República presenciado por delegaciones y mandatarios de otras naciones.

Estos casos nos demuestran la existencia de un debate con respecto a cómo y qué se entiende por folclore en Chile, una discusión que ha circulado por todo el siglo XX y que sin duda proyecta sus posturas hacia el siglo XXI, cuando camino al bicentenario se hace necesario repensar los conceptos de patria y de nación que se proyectaron doscientos años atrás.

Las tensiones que provocan las definiciones con respecto al folclore se relacionan con una concepción de éste vinculada a la idea de nación. Tal como lo ha definido Eric Hobsbawm, el estudio de las ciencias relacionadas con el pasado cultural de un pueblo fueron utilizadas para crear un imaginario de "comunidad nacional” que posee un pasado común, considerando lo que supuestamente une a una nación y lo que la diferencia de las otras ${ }^{7}$. Asimismo, el investigador argen-

${ }^{6}$ Oficio N ${ }^{\circ} 4878$, de la Cámara de Diputados al Ministerio de Educación. 15 de marzo de 2000. Esta polémica ha sido analizada por Rodrigo Torres en "El arte de cuequear: identidad y memoria del arrabal chileno" (Torres 2003). Cristi fue apoyada en este reclamo por Alberto Cardemil, latifundista y autor del libro El huaso chileno (Cardemil 2000).

${ }^{7}$ Hobsbawn y Rangers 2002: 278. 
tino Carlos Vega planteó que "la emoción de lo folclórico, como estímulo, está teñida de un sentimiento de propiedad por herencia de próximos antepasados, se mueve en un ámbito estatal, fundamenta el fervor de los tradicionalistas, apareja ideas de nacionalismos con episodios de imitación y comporta intereses de orden político o estético o moral o todo junto" 8 . Las expresiones folclóricas, entonces, han sido absorbidas por el discurso de la nación, lo que ha implicado la exclusión de algunas manifestaciones de este ámbito, pues simplemente no serían folclóricas las adivinanzas, o serían seudofolclóricas como plantearía un investigador posteriormente ${ }^{9}$. En otros casos, ha habido una inclusión pero con un proceso de "limpieza" previo de los rasgos populares, modificando las manifestaciones para que sean concordantes con un discurso nacional, el que implica la existencia de mitos, imágenes, símbolos, rituales y, por supuesto, una historia nacional gloriosa.

En este sentido, los debates en torno a la definición y comprensión del folclore han estado vinculados con la idea de nación, pero también con la forma de pensar al pueblo y la cultura popular. El investigador Rodolfo Lenz, junto a otros estudiosos, fundó en 1911 la Sociedad del Folklore Chileno, optando por una definición netamente popular del folclore, explicando que el objetivo de esta ciencia era el estudio del alma popular ${ }^{10}$. Desde este punto de vista, creemos que las discusiones en torno a la definición del folclore se enmarcan en dos grandes líneas interpretativas, ya sea definiendo al folclore como patrimonio de la nación o comprendiéndolo como forma expresiva de la cultura popular. Esta grande y compleja discusión tuvo un momento álgido durante los años de la dictadura militar, pues, entre 1973 y 1990, lo que era un debate asumió la forma de imposición-resistencia, debido a que las interpretaciones nacionalistas y cosificantes se impusieron por ser coincidentes con las políticas culturales del gobierno militar. En tanto, la otra mirada más concordante con un folclore del mundo popular se continuó desarrollando de manera subterránea, como una forma de resistir dicha imposición. La batalla del folclore se dio por mostrar la cara del otro pueblo, aquel que no sólo fue idealizado por la dictadura, sino el pueblo que vivía su propia cultura, aún y a pesar de ser un período de fuerte control social desde el aparato gubernativo. Se reivindica, en este caso, la existencia de un arte-vida que permaneció vigente en el mundo popular.

En estas páginas presentaremos el trabajo realizado por algunos exponentes de estas líneas interpretativas, que hemos seleccionado, pero que forman parte de un discurso mayor construido colectivamente por más sujetos a lo largo del siglo XX. En el período seleccionado, veremos cómo ambas líneas interpretativas se manifestaron en tres espacios: el de las políticas culturales, el mundo académico y el mundo artístico.

\footnotetext{
${ }^{8}$ Vega 1959: 84 .

${ }^{9}$ Dannemann 1960: 207.

${ }^{10}$ Donoso 2006. capítulo 1 .
} 


\section{EL FOLCLORE Y LA OFENSIVA NACIONALISTA DE LA DICTADURA MILITAR}

El orden que se erigió luego del golpe de Estado de 1973 conllevó la imposición de formas culturales que tenían un doble objetivo. Por un lado, erradicar la cultura de izquierda, con tintes revolucionarios y libertarios, a través de la represión y, por otro, restaurar el imaginario mítico del Chile unido que había quedado perdido en el siglo XIX. Según la interpretación que hizo el historiador conservador Gonzalo Vial, el gobierno de Allende fue el momento culmine de la crisis de unidad nacional que se venía desarrollando desde comienzos del siglo XX, debido a la ruptura de los consensos sociales, políticos y culturales, al aparecer doctrinas que dividieron a la nación. Este discurso fue el que recogió la junta militar pues, al justificar el golpe de Estado, uno de los elementos aludidos era justamente el quiebre de la unidad nacional, por lo tanto, las Fuerzas Armadas asumieron el "deber moral que la patria le ha impuesto" de reconstruir la integridad espiritual del país: "El gobierno de las Fuerzas Armadas y de Orden, con un criterio eminentemente nacionalista, invita a sus compatriotas a vencer la mediocridad y las divisiones internas, haciendo de Chile una gran nación. Para lograrlo, ha proclamado y reitera que entiende la unidad nacional como su objetivo más preciado y rechaza toda concepción que suponga y fomente un antagonismo irreductible entre las clases sociales" 11 .

Bajo estos fundamentos trabajaron los civiles nacionalistas en las oficinas encargadas de la cultura y el arte. Las políticas culturales emanadas desde aquellos puestos de trabajo fueron coherentes con una mirada conservadora del folclore, que proponía una definición de éste como disposiciones esenciales que estaban en diálogo con los fundamentos de la nación y su cultura, los "verdaderos valores tradicionales", seleccionando principios que caracterizarían una auténtica y originaria identidad nacional. Desde esta mirada, se entiende que la identidad nacional es un "deber ser", surgido de la selección de los "mejores y reales valores" que caracterizan a lo chileno, coincidente con la cultura cristiano-occidental-blanca ${ }^{12}$.

Desde esta mirada esencialista de la cultura, se realizó una interpretación "funcionalista" del folclore, que se encaminaba a colaborar en el restablecimiento de la supuesta identidad nacional perdida. Pero la concepción de folclore elegida era la recién descrita, lo cual implicó erradicar todas aquellas interpretaciones "subversivas" y "marxistas" que impregnaron al folclore en la década de 1960. De ahí que la construcción de un nuevo concepto se produjo a la par de la destrucción del otro: se detuvo a artistas vinculados al mundo del folclore y la música, se terminó con la carrera de instructor de folclore en la Universidad de Chile y se exoneró a profesores de la misma institución, se depuró el Ballet Folclórico Nacional, y el caso más simbólico de la destrucción física de ese otro concepto fue la muerte de Víctor Jara el 14 de septiembre en el Estadio Chile ${ }^{13}$.

${ }^{11}$ Tesis de Gonzalo Vial, en Vial 1984. Vial fue Ministro de Educación en 1979 y principal defensor del golpe de Estado como una crisis de larga data. Primera cita de "Bando $N^{\circ} 5,11$ de septiembre de 1973”, Garretón 1995: 59. Segunda cita "Declaración de principios del Gobierno de Chile” 1974: 11.

12"Política cultural del Gobierno de Chile" 1975: 19.

${ }^{13}$ Donoso 2008: 238-239. 
Con el fin de contar con más antecedentes de la situación que afectaría a los artistas en el nuevo gobierno, el Sindicato de Folcloristas (agrupación que se formó en la década de 1950) concertó una reunión con el Secretario General de Gobierno, en la cual los militares precisaron cuál sería el tipo de folclore que se aceptaría. Así lo relató el folclorista Héctor Pavez en una carta enviada a René Largo Farías, en uno de los pocos testimonios que existen sobre este hecho:

\begin{abstract}
"Nos dijeron la firme: Que iban a ser muy duros. Que revisarían con lupa nuestras actitudes, nuestras canciones. Que nada de flauta, ni quena, ni charango, porque se identificaba con la lucha social. Que el folklore del norte no era chileno. Que la Cantata de Santa María de la cual es autor el Lucho Advis, era un crimen de "lesa patria", en este momento supimos que Lucho estaba en la capilla. Que si Ángel Parra, era inocente como blanca paloma, como blanca paloma volaría... Que Quilapayún era responsable de la división chilena... luego los elogios. Habló maravillas del estilo de canto del Cuncumén, que solamente se difundiría este estilo, y un piropo, que yo lo sentí como una invitación directa a colaborar con ellos, pues me dijeron que también podía yo con mucha propiedad difundir el folklore chilote"14.
\end{abstract}

Por lo tanto, las políticas culturales de la dictadura militar, realizaron su reinterpretación del concepto folclore a partir de la extirpación de los elementos "indeseables" y la difusión de un concepto recreado a partir de las definiciones de lo folclórico-nacional-esencialista que ya existían. Acorde con ello, el gobierno militar no creó nada, pues todas las manifestaciones folclóricas que pasaron a ser parte del discurso oficial, ya se habían desarrollado a lo largo del siglo XX. La interpretación esencialista del folclore que emanó de las políticas culturales del gobierno militar se manifestó en tres áreas: la recreación del huaso, el folclore como ciencia y el folclore como espectáculo.

\title{
La recreación del huaso
}

Una de las vertientes discursivas que nutre la mirada oficial del folclore es la reinterpretación del huaso. En el lenguaje cotidiano y popular el término "huaso" se usa de manera peyorativa para ofender la torpeza de alguien, principalmente si no pertenece a la ciudad. Incluso, a comienzos de siglo, el huaso tenía la misma definición de roto, diferenciándose ambos en que el huaso era campesino y el roto era más cosmopolita, podría estar en la ciudad o en el campo, o haber sido migrante. Sin embargo, durante el siglo XX se recreó un imaginario del huaso que buscaba dividir la sociedad en clases sociales y diferenciar esta imagen de la del roto, como el pobre. Esta distinción fue explícitamente explicada por René León Echaíz, quien en la década de 1950 planteó que el huaso era el "mestizo ascendente”, aquel que se educó con su padre español y que logró captar las

14“Carta de Héctor Pavez a René Largo Farías", París, 3 de julio de 1975. Le agradecemos a Héctor Pavez Pizarro el préstamo de este valioso documento; una versión reducida de esta carta se encuentra en Largo Farías 1977. En el diario Tribuna, perteneciente al Partido Nacional, se informó que esta reunión se había concertado por parte de los folcloristas "en apoyo" al gobierno militar, situación completamente desmentida por Pavez. 
tradiciones hispánicas; en tanto que el roto era el "mestizo descendente", aquel que se crió en su ambiente materno-indígena y que es "vicioso e indolente, y como el indio, y como él, no puede resistir al alcohol y a la embriaguez, por un proceso confuso y ancestral" 15 . Esta definición civilizatoria, busca diferenciar entre lo tradicional aristocrático y lo tradicional popular.

La historiadora María Rosaria Stabili analizó las formas en que la elite terrateniente se sentía identificada con un imaginario del huaso, que apelaba a la hidalguía del español, la austeridad, la sencillez, siendo su principal vínculo con la tierra, el fundo o el latifundio que los formó identitariamente ${ }^{16}$. A partir de este basamento se ha construido una imagen mítica del huaso y del mundo agrario, como una sociedad jerarquizada pero armónica, donde convivían idealmente el patrón -el huaso con chamanto y espuelas de plata- con el inquilino -el huaso con manta y ojotas. Conviven y comparten, pero cada uno en su lugar.

De ese imaginario del mundo agrario es que emerge el perfil del huaso que se expresa en la década de 1920 en la corriente musical iniciada con el grupo Los Cuatro Huasos. Este conjunto, que nació de las inquietudes musicales de cuatro jóvenes, algunos estudiantes universitarios, alcanzó un éxito inesperado en la industria musical al recrear ese ideal mítico, cantando a los amores y paisajes agrarios. De este grupo se desprende una línea artística que posteriormente retomarían otros, como Los Huasos Quincheros, formado en 1937 y aún vigente ${ }^{17}$. En efecto, fue este conjunto el que representó el folclore dentro de la dictadura militar, siendo parte activa de sus aparatos culturales, tal como Benjamín Mackenna -miembro de los Huasos Quincheros- participó desde 1974 en la Secretaría de la Juventud y en 1977 en la Secretaría de Relaciones Culturales. Los Quincheros se integraron al Comité de Recreación de las Fuerzas Armadas y además participaron de las actividades que se hicieron para reunir fondos para la "Reconstrucción Nacional" con posterioridad al golpe de Estado ${ }^{18}$.

Su propuesta artística fue desarrollada junto a Germán Becker -productor de espectáculos musicales- y tenía como objetivo difundir los principios de la identidad nacional, con un "alto contenido nacionalista, pero en forma sencilla para llegar al público"19. Esta alusión a la sencillez buscaba poner el folclore en el escenario, pues en su "estado natural" sería "aburrido" y, por lo tanto, no atraía al público. Refiriéndose a la delegación chilena que participaría en el acto inaugural del campeonato mundial de Alemania 74, Becker señaló que "sería muy folclórico llevar a Alemania a los poetas populares. Pero son viejecitos desdentados que cantan 20 minutos sin parar. Tengo que llevar artistas de exportación..."20.

\footnotetext{
${ }^{15}$ René León Echaíz (1914-1976) fue Intendente de Curicó durante el gobierno de Jorge Alessandri (1960-1963), y presidente de la Sociedad de Historia y Geografía durante la década de 1970. Ver León Echaíz 1995: 19. Sobre esta misma distinción Mariano Latorre (otro escritor criollista) planteó que "el huaso está enraizado en la tierra, es conservador, enemigo de reformas, obstinado y creyente; en tanto que el roto es anárquico, ateo, indeterminado e irrespetuoso" (Latorre 1969: 7).

${ }^{16}$ Stabili 2003.

${ }^{17}$ Sobre los Cuatro Huasos y su desarrollo en la industria cultural ver Rengifo y Rengifo 2008.

${ }^{18}$ Donoso 2008: 242-243.

${ }^{19}$ Qué Pasa 1976: 58.

20Ercilla 1974: 43.
} 
Esta forma de concebir el folclore, que ya venían desarrollando los Huasos Quincheros desde su fundación, fue acogida desde el gobierno militar, toda vez que ellos plantearon que: "Ahora la cosa es absolutamente distinta; este gobierno quiere que la canción chilena sea una sola. No comprometida, sino sólo con los valores de nuestra patria y ponerla a un nivel mundial digno y de importancia. Si aparecemos ligados a quienes nos dirigen es porque compartimos plenamente las metas y los enfoques que ellos dan a nuestro folclore"21.

Otra forma que tuvo el régimen de recrear el imaginario del huaso fue a través de la promulgación del Decreto Supremo N 23 que declaraba la cueca Danza Nacional de Chile, pasando a formar parte de los símbolos nacionales, que hasta ese entonces incluía la bandera, el escudo y el himno ${ }^{22}$. Este decreto responde a las solicitudes de la Federación Nacional de la Cueca (FENAC), agrupación que desde 1969 organiza el Campeonato Nacional de Cueca en la ciudad de Arica y que trabajó junto al gobierno en la realización de este torneo y de otras instancias como la Casa de la Cueca, el Encuentro de la Cueca Diego Portales y la creación de Clubes preparatorios para esta actividad ${ }^{23}$.

Relacionamos este decreto con la reinterpretación del huaso porque la cueca que se consagró como danza nacional fue una expresión particular de ésta: la cueca huasa. En el decreto se afirmaba que el Ministerio de Educación tendría como misión organizar anualmente un concurso nacional para los estudiantes primarios y secundarios. Es así como se realizaron -y financiaron- concursos y campeonatos en todo el país en los que se difundió el estilo de cueca huasa, pues el vestuario exigido era el de "china" y "huaso" y se crearon esquemas universales para la danza, cumpliéndose estas condiciones para los participantes de Arica o Punta Arenas, ignorando las formas regionales que adquiere esta danza.

La cueca que se oficializó fue una cueca uniformada, estilizada, depurada y purgada de interpretaciones populares, ignorando no sólo las expresiones regionales y locales, sino también la "cueca chilenera" que se reproducía entre los sectores populares citadinos ${ }^{24}$. Según las declaraciones de Osvaldo Barril, dirigente de FENAC, la cueca "soportó insultos y vejámenes, e incluso fue excomulgada por grosera, por lasciva y ordinaria [...]. Nunca perdió su dignidad porque no era ella la grosera y ordinaria, sino quien la interpretaba" 25 . Por lo tanto, para darle la categoría de danza nacional fue necesario extirparle lo "grosero". Fue

${ }^{21}$ L a Segunda 1974: 44.

${ }^{22}$ Valencia Avaria 1974.

${ }^{23}$ Donoso 2006: 117. El organismo gubernamental que colaboraba con la FENAC era la Secretaría de Relaciones Culturales, y la participación consistía en financiamiento y apoyo en permisos y gestión de las actividades. Esta Secretaría también se involucró en los Festivales de Folclore de San Bernardo, de La Patagonia y de Olmué, ofreciendo la misma ayuda, e incluso participando en el comité organizador.

${ }^{24}$ Alegría 1981: 125. Este artículo explica, en pleno auge del decreto, cómo la cueca chilenera no tiene cabida en los medios de comunicación, habiendo sido lo más cercano la participación del cuequero Hernán Núñez junto al grupo Aparcoa en el Festival de Viña de 1972. Si bien en la década de 1960 se vivió un momento en que se grabaron discos con cantores populares de cueca chilenera, sólo en la década de los 90 se vive un real reconocimiento de este patrimonio cultural, aún muy popular.

${ }^{25}$ Revista Proyección de la Cultura 1989: 17. 
este modelo de cueca el que se difundió en escuelas y colegios de todo el país, educándose los niños de la década de los 80 con este imaginario de lo folclórico.

\section{El folclore como ciencia}

Las definiciones del folclore como ciencia en América Latina provienen del investigador argentino Carlos Vega, quien se constituyó en un paradigma para los análisis de esta disciplina. En Chile las líneas de estos fundamentos se instalaron en la Universidad de Chile en la década de 1940, cuando se creó el Instituto de Investigaciones Folclóricas, que luego pasó a ser parte del Instituto de Investigaciones Musicales. Allí se dieron cita investigadores provenientes de la filología y la historia, quienes desarrollaron sus investigaciones en terreno iniciando un período de ciencia y proyección del folclore que no se cerraría hasta la década de 1960. A este grupo pertenece Manuel Dannemann, investigador que se formó bajo esta escuela y que elaboró su teoría del folclore, a partir de sus primeras publicaciones en la década de 1960.

La teoría del folclore de Dannemann fue coherente con el discurso cultural del gobierno militar. A partir de los postulados teóricos del folclore como ciencia, logró justificar la exclusión de lo popular de la definición misma del folclore, el que fue entendido a partir de dos conceptos claves: el "hecho folclórico" y la "comunidad folclórica". Un hecho folclórico, en esta interpretación, era aquel bien cultural que siendo usado por los hombres de una sociedad provoca un sentido de pertenencia con una tradición cultural y, por lo tanto, una identificación con este bien y con el resto de la comunidad que lo utiliza. Se caracterizaría principalmente por ser de uso y entendimiento de una comunidad, entiéndase ésta no como un sector geográfico o un colectivo, sino como un grupo humano que comparte los mismos bienes folclóricos pero no necesariamente poseen las mismas condiciones sociales o económicas. Bajo estos supuestos, los bienes folclóricos no corresponderían a una comunidad o a una clase social concreta, sino que son patrimonio de toda una sociedad; pero, se hace comunidad folclórica cuando en algún momento específico se usan hechos folclóricos cumpliendo con la función de identificar y generar sentido de pertenencia ${ }^{26}$.

Esta forma de concebir el folclore permite darle más importancia a lo que une a una comunidad, que puede ser de un pueblo, de una región o de una nación, buscando aquellos elementos comunes a esa sociedad. Con este argumento se comprende que Dannemann, en un estudio publicado en 1974, considere que las canciones "Yo tenía un camarada" (marcha militar) o "Adiós al Séptimo de Línea” (creada en la década de 1960) sean parte del patrimonio folclórico de la nación chilena, pues según su interpretación, contribuirían a fortalecer la identificación entre la comunidad nacional ${ }^{27}$.

Siguiendo el mismo argumento, este autor también propuso la necesidad de crear una verdadera "ciencia del folclore" que diera cuenta de los hechos folclóricos

\footnotetext{
${ }^{26}$ Dannemann 1998: 47-52.

${ }^{27}$ Dannemann 1975: 57 y 70.
} 
que representaran los "verdaderos valores tradicionales", pues sin una política cultural que apunte a la protección de estos bienes existe el riesgo de perderlos, proceso que ya se estaba produciendo: "Y así, ha destruido, irremisiblemente, no sólo una gran cantidad de música tradicional, sino que también y en alto grado, elementos de la conciencia y la acción de una verdadera chilenidad, los que fueron forjados después de un lento y difícil proceso de selección y depuración de los valores nacionales y regionales distintivos" ${ }^{28}$. En este artículo citado, no se hace referencia a cómo se desarrolló ese proceso de "selección y depuración", pero con esta frase da a entender que para estas fechas ya existe una especie de "repertorio" o "catálogo" folclórico, donde se han seleccionado una serie de festividades, canciones, rituales que sería necesario revitalizar, conservar y potenciar, instando a la existencia de una política cultural que se haga cargo de esta tarea, la que nominó como "intervención"29.

Con este planteamiento Dannemann se distancia de las definiciones que vinculan el folclore con el patrimonio de un sector social específico, el popular. En su interpretación, el folclore pertenecería a toda una sociedad, y no sólo al mundo popular, contribuyendo también con esta mirada a fortalecer el imaginario de la unidad nacional, siendo el folclore uno de sus elementos sostenedores. Aunque Dannemann no plantea explícitamente esta problemática, se desprende de su interpretación que lo importante en esta lectura son los "hechos folclóricos" y no el grupo social donde éstos se reproduzcan, no las personas que lo vivencien, pues éstos conviven en una comunidad que aparece y desaparece cada tanto.

\section{El folclore como espectácu lo}

$\mathrm{Al}$ igual que los elementos anteriores, la difusión del folclore como espectáculo durante el gobierno militar se hizo a partir de aceptar una interpretación del folclore que ya se venía desarrollando. El folclore como espectáculo aparece durante la década de 1960, cuando la música y la danza folclórica se transforman en objetos rentables para la industria comercial y cuando se comenzaron a crear conjuntos y ballets folclóricos que pretendían llevar a un escenario aquellos ritmos antiguos, pero adaptados a los nuevos tiempos: la música se arreglaría para el canto grupal y la danza se coreografiaría para la proyección en un escenario y con varias parejas de bailarines sobre él.

Esta forma de comprender el folclore tomó distintas vías. Desde las políticas culturales del gobierno militar se acogieron aquellos grupos que asumieron la proyección del folclore desde un "sentido del espectáculo", en sintonía con lo planteado por Becker y los Quincheros. El grupo que logró ser la máxima expresión de esta forma de escenificar las danzas folclóricas fue el Ballet Folklórico Nacional (BAFONA), que tiene sus orígenes en el Ballet Folclórico Aucamán, nacido en 1965 con estudiantes del Instituto de Educación Física de la Universidad de Chile y que en 1969, ya dividido, se integró como parte del Ministerio de Educación, con

\footnotetext{
${ }^{28}$ Dannemann 1975: 83.

${ }^{29}$ Dannemann 1978: 17-19.
} 
el nombre de Ballet Folclórico Nacional. Después del golpe de Estado el BAFONA fue reestructurado, con la exoneración del director y varios bailarines.

En general, los ballets folclóricos chilenos recibieron influencia artística de los ballets rusos y mexicanos durante la década de 1960, de los cuales rescataron el colorido, la coordinación y la gran puesta en escena, en la que los bailarines resaltan por su estética, agilidad y destreza. A partir de 1979, cuando se lleva a cabo la segunda reestructuración del BAFONA, es posible observar el despliegue de los objetivos del folclore-espectáculo, tal como desde los mismos medios de comunicación del gobierno se explicitaba: "este elenco ha dignificado nuestro folclore, al darle un nivel de excelencia artística y profesional a su espectáculo, sacó al folclore del reducido ámbito de las manifestaciones autóctonas espontáneas y logró concitar el entusiasmo del público chileno y extranjero" ${ }^{30}$. La fórmula para conseguir este "éxito" la entregó su director, Pedro Gajardo en 1985, cuando le explica a la prensa que su dirección se caracterizaría por hacer tres exigencias básicas al elenco: "un alto porcentaje de raíz folclórica... 75\% aproximadamente, un alto sentido del espectáculo y un lenguaje universal, basado en elementos escénicos, teatrales que les permitiera llegar al extranjero"31. Desde esta mirada se aprecia que el folclore debe ser "adaptado" para ser llevado a un escenario y tener "éxito", para competir con otras áreas de las bellas artes, como una orquesta. El folclore en su estado puro no es "artístico" y no era rentable. Por lo tanto, se debía adaptar y modificar según este razonamiento.

A partir de la aparición de numerosos conjuntos folclóricos que buscan emular la fórmula BAFONA desde la década de 1980, es que en el lenguaje cotidiano y popular el concepto folclore cambió su significado original y transformó su definición, para ser como la "sabiduría popular" 32 se presenta en un escenario. Lo folclórico, entonces, correspondería a lo que hacen los conjuntos y ballets.

En suma, las políticas culturales de la dictadura militar acogieron tres formas de comprender el folclore que siguen la misma línea interpretativa: la lectura de lo folclórico como hechos y tradiciones que forman parte de una identidad nacional, comprendida como una esencia y apelando a un pasado común que genera un sentido de pertenencia. Con ello, se le niega su historicidad y se le saca la matriz popular creadora y vivenciadora de estas experiencias. Cabe recalcar que estas tres manifestaciones no fueron creadas por el gobierno militar. Éste sólo las incorporó como parte de sus políticas culturales.

\section{EL FOLCLORE COMO ARTE VIDA DEL PUEBLO}

En paralelo con la imposición de la ya mencionada interpretación del folclore, las autoridades del gobierno militar iniciaron la persecución y represión de los artis-

${ }^{30}$ Diez Años de Extensión Cultural 1987: 67.

${ }^{31}$ QuéPasa 1985: 44. Pedro Gajardo dejó la dirección del BAFONA a fines de la década de 1980, para formar un elenco con las mismas características llamado Ballet Folclórico de Chile, BAFOCHI.

${ }^{32}$ Es sabido que la voz "folclore" deviene del compuesto inglés "folk=pueblo" y "lore=sabiduría". Sin embargo, la definición del folclore como espectáculo de cantos y danzas está bastante arraigada entre la población. 
tas vinculados a la izquierda y a la Unidad Popular. Durante el gobierno de Salvador Allende también se trató de difundir un concepto de folclore desde el punto de vista artístico, vinculándolo a la cultura popular y a la construcción del socialismo. El folclore se reivindicó por su evocación del sentimiento popular y nacional, revalorizándose los ritmos y estéticas populares que habían sido ignoradas por la versión huasa de la cultura chilena, como la música andina, chilota y campesina popular. Por ello, la represión se dirigió hacia este tipo de concepciones y expresiones del folclore, pues, según la explicación de Héctor Pavez en la carta citada, los militares tenían bastante claro qué tipo de música nacional iban a difundir.

En esta sección trataremos a algunos investigadores y artistas que defendieron y trabajaron en torno a una interpretación del folclore que retomó el legado de la matriz popular desarrollada desde la generación de 1910. Debemos precisar que dentro de este grupo de investigadores y folcloristas, no sólo se desarrolló una nueva forma de reivindicar el folclore, sino que también surgió un nuevo concepto para nominar a la cultura folclórica, frente a la arremetida del folclore-espectáculo. El concepto ya no hacía referencia ni a la disciplina ni a un tipo de manifestaciones culturales, sino que estaba aludiendo a una puesta en escena. Poco a poco se comenzó a hablar de la cultura tradicional popular como una forma de distanciarse de la mirada esencialista, cosificante y de espectáculo de la cultura folclórica. Hay dos rasgos que se repiten en los casos que veremos: el regreso a la matriz popular, concibiendo el folclore como patrimonio del pueblo, un pueblo que en este contexto de autoritarismo vive la represión, la pobreza y el control estatal, y el estudio no sólo de los "hechos" o "materiales folclóricos" sino también de las personas que viven esa cultura. En esta lectura hay una preocupación por las mujeres y los hombres que la vivencian, corporizando las manifestaciones folclóricas.

\section{Dela academia al campo}

En esta línea interpretativa surge desde el mundo académico una óptica que no intenta construir una teoría sino que se estudia a partir de la experiencia de los cultores, de quienes son portadores del repertorio folclórico tradicional y que lo han ido revitalizando en un intento por perpetuarlo. Uno de éstos fue Juan UribeEchevarría (1908-1988), discípulo de don Mariano Latorre, a quien él mismo reconoció como un maestro que le "abrió la visión de nuestros valores nacionales", lo cual le permitió más tarde "descubrir al inquilino y al roto" 33 , que fueron los personajes por los cuales finalmente se inclinó. Uribe-Echevarría explicitó su distanciamiento con la mirada criollista sobre el campo chileno, y se abocó a estudiar al hombre, a la mujer, al poeta, al cantor y al danzante, haciendo trabajos en terreno, combinados con la investigación de fuentes escritas tales como crónicas de viajeros, oficios, cartas, prensa y la poesía popular impresa.

Este investigador creía que los costumbristas cultos, en su mayoría, observaban las fiestas del pueblo sin participar, con distancia e incluso con menosprecio, en tanto que para comprender las tradiciones y el alma del pueblo, era necesario

\footnotetext{
${ }^{33}$ Ercilla 1966: 29
} 
convivir con ellos, conocer a los poetas populares, separar la brecha que existe entre un investigador y su objeto de estudio. El folclore era la vida, y esa vida debía ser experimentada para conocerla ${ }^{34}$. Es por ello que estableció relaciones de amistad y compañerismo con algunos poetas populares, a quienes llevó a los recintos universitarios y a la Biblioteca Nacional, para darlos a conocer más allá de su espacio natural de desempeño. Esta fue la experiencia que compartió con Santos Rubio de Pirque y Manuel Gallardo de Aculeo, entre otros ${ }^{35}$.

Uno de los legados de Uribe-Echevarría fue su forma de escribir sus trabajos de investigación, en los cuales junto a las colecciones de poesía popular recogida se individualizó la obra de los poetas, destacando y describiendo con detalles las virtuosidades de cada cantor, su capacidad para improvisar, para memorizar, entonar, componer y nutrir permanentemente el repertorio tradicional. Entre estos trabajos se destacan Contrapunto de Alféreces en la Provincia de Valparaíso publicado en 1958, el Cancionero de Alhué de 1964 y M anuel Garrido, cantor glorioso de 1965. Durante los años 70, Uribe-Echevarría continuó publicando. Dentro de la línea descrita se destaca Flor de canto a lo humano, en el que se incluyen fotografías y descripciones de los cantores y poetas populares.

Esta forma de trabajar con el mundo popular desde la academia fue utilizada también por Fidel Sepúlveda Llanos (1936-2006), quien se acercó al estudio de la cultura popular a partir de la literatura, sobre la base de la convivencia con los poetas populares. Sepúlveda, sin embargo, desarrolló su trabajo de investigación y difusión dentro del Instituto de Estética de la Universidad Católica aplicando sus conocimientos también en la docencia y fue uno de los gestores de la Escuela Nacional del Folclore en Concepción y de las ulteriores Escuelas de Temporada de Cultura Tradicional en la Universidad Católica de Santiago, las que se constituyeron en el único espacio de enseñanza de métodos de investigación y proyección del folclore durante los años ochenta.

Sepúlveda propuso romper con la interpretación esencialista del folclore y proporcionó los fundamentos para comprender el folclore como el "arte-vida" que existe en el pueblo y permanece vivo debido a la permanente interacción entre los bienes culturales "antiguos" y los "nuevos". La tradición, para Sepúlveda, nunca es sólo pasado, la tradición vive cuando se nutre de lo nuevo y eso nuevo puede reinterpretar o revitalizar la forma de las tradiciones, al momento que se produce el encuentro de "los signos del presente con los del pasado y desde ahí proyectar al futuro" 36 . A partir de este diálogo es que este investigador plantea que la tradición se vive en un tiempo vital más lento, lo que denominó la "transhistoria", el tiempo de las cosmovisiones culturales y sus ejes, que trasciende

\footnotetext{
${ }^{34}$ Uribe-Echevarría 1974: 20. Ver además Uribe-Echeverría 1973: 108.

${ }^{35}$ La relación de Juan Uribe con los poetas se puso en evidencia en la actividad denominada "Cueca larga para don Juan. Homenaje a Juan Uribe Echeverría”, realizada el 28 de junio de 1989 en la Sala América de la Biblioteca Nacional. En aquella oportunidad los poetas populares entregaron sus testimonios y comentaron el trabajo realizado por este investigador. El material audiovisual producido durante ese evento se encuentra disponible en el Archivo de Literatura Oral y Tradiciones Populares. Le agradecemos a Micaela Navarrete el acceso a este material.

${ }^{36}$ Sepúlveda 1985: 45.
} 
la intrahistoria (el tiempo personal de cada individuo) y la interhistoria (el tiempo de la sociedad), explicando la razón de por qué las tradiciones permanecen en el tiempo por varias generaciones.

La propuesta de Fidel Sepúlveda apuntaba al folclore como "experiencia humana" y no como "hechos folclóricos", pues no existían esos hechos sin las personas que los ejecutan o que les dan sentido. Por lo tanto, se debía hablar de comportamientos, pues los hechos o materiales no son permanentes, se van recreando, reproduciendo en cada generación. Así pues, lo que permanece es el sentido que éstos adquieren. Pero también estos comportamientos se viven en tanto una comunidad lo experimenta, se lo apropia y le otorga sentido. Sepúlveda planteó que el arte folclórico era un arte comunitario, por lo tanto abierto, porque su autor era colectivo y una obra se recrea cada vez que es interpretada; pero también planteó que era abierto porque eran obras que permanentemente se estaban haciendo: "la obra folclórica ocurre por una creación sucesiva. Su condición óntica es el ser proyecto-trayecto, ser siendo lanzado adelante permanentemente, análoga al proyecto-trayecto que es el hombre como especie, en diversas comunidades, lugares y tiempos" 37 .

Sepúlveda asumió que la elite chilena se autopercibió como una elite blanca y despreció la herencia indígena dentro del pueblo. No obstante, este investigador consideró que la cultura popular no sería reprimida, sino que poseería una riqueza creativa que permanecía oculta pero que seguía reproduciéndose. En sus palabras, la cultura tradicional popular "no es subalterna, sino principal, no es periférica, sino central, no está caduca sino que es modo permanente de encuentro del hombre con su sentido, al concordar la lectura de los signos del presente con los del pasado y desde ahí proyectar su futuro" 38 , intentando colocarla en un sitial importante para su estudio y comprensión, a partir de su propia capacidad para construir historia.

\section{El folclore de campesin os y pobladores}

En diálogo con las definiciones anteriores Gabriela Pizarro y Patricia Chavarría desarrollaron un trabajo de investigación y proyección artística del folclore. Las hemos elegido para representar esta interpretación, puesto que, desde nuestro punto de vista, Gabriela Pizarro constituye por sí misma una escuela de búsqueda y proyección del folclore, muy influenciada por Violeta Parra, óptica que además logró enseñar e infundir a sus compañeros y discípulos, como es el caso de Patricia Chavarría ${ }^{39}$. Ambas se dedicaron a trabajar la investigación y proyección artística del folclore fuera de los espacios universitarios y de los medios de comunicación.

\footnotetext{
${ }^{37}$ Sepúlveda 1983: 16.

${ }^{38}$ Sepúlveda, 1985: 45.

${ }^{39}$ Patricia Chavarría conoció a Gabriela Pizarro a fines de los años sesenta, y se presentó como su alumna y con ganas de aprender. Chavarría desarrolló su trabajo de investigación en las regiones del Maule y Bío-Bío. En ese entonces, Chavarría dirigía el conjunto Aucán, con el cual hicieron algunas representaciones llamando la atención de la prensa santiaguina porque sus integrantes no usaban "trajes" sino que vestían sus prendas de trabajo de mineros y peones.
} 
Gabriela Pizarro comenzó a trabajar con el folclore en la década de 1950, expresando sus inquietudes por la música y el canto desde muy joven. Ingresó como alumna a los cursos que dictaba Margot Loyola en las Escuelas de Temporada de la Universidad de Chile. Luego, junto a Héctor Pavez Casanova formó el conjunto Millaray, en el que buscaron proyectar las expresiones del folclore musical campesino de la zona central y del archipiélago de Chiloé. La propuesta artística de este conjunto fue representar la festividades populares y también mantener la sonoridad del canto en su lugar de origen, utilizando como instrumentos musicales botellas, tarros, cajones y cuanto hubiera a mano para reproducir el estilo de canto tal como era aprendido ${ }^{40}$.

Gabriela Pizarro vinculó su trabajo artístico con una función política y por ello participó en la campaña de Salvador Allende de 1964 y 1970, lo cual ella explicó posteriormente con estas palabras:

"Y nosotros no somos del aire, ¿no? Porque pertenecemos a una clase social, y estamos conectados con el campesinado, la experiencia del pueblo y del trabajador, a nosotros nos ubicó en una posición política en una posición social... Nosotros luchamos por los trabajadores porque ellos nos enseñaron y la música de ellos es la que estamos cantando, y los bailes de ellos es lo que estamos mostrando" 41 .

Su vínculo con la Unidad Popular la hizo replegarse después del golpe de Estado; fue exonerada de la Universidad de Chile, donde hacía clases, y ella misma relata que sólo pudo retomar la guitarra y el canto con los niños de la población La Faena, donde vivía, quienes le pidieron cantar villancicos para la Navidad ${ }^{42}$.

Por su parte, Patricia Chavarría estuvo detenida después del golpe de Estado, y al salir retomó la guitarra, la búsqueda del canto campesino y sus clases de folclore musical en la Corporación Cultural Artistas del Acero. El principal vínculo que estableció Patricia Chavarría fue con las cantoras campesinas, también individualizando su repertorio y estudiando su función, sus tradiciones, creencias, costumbres al momento de tocar la guitarra. Logró establecer relaciones de amistad que la hicieron suponer que ella era la que aprendía en el pueblo y no al revés. Se borra la distancia entre el investigador y el objeto de estudio, pues Patricia Chavarría pasó a ser aprendiz de las cantoras, quienes la acogieron como una más.

Gabriela Pizarro, por su parte, así como trabajó con las cantoras campesinas, también desarrolló una búsqueda de la cultura popular en las poblaciones de Santiago. Ella reconoce que en la población La Faena recopilaba textos, adivinanzas, experiencias y de un "cuantohay" en todas partes; en las fiestas, los negocios,

${ }^{40}$ Para apreciar esta forma de trabajo se puede escuchar el disco del conjunto Millaray La Ramada, Serie El folclore de Chile, vol. XXVI, Santiago: Sello Emi-Odeón, 1971.

${ }^{41}$ Chile Ríey Canta 1992: 21.

${ }^{42}$ Es necesario mencionar el trabajo realizado por Gabriela Pizarro en 1978, cuando creó la obra "Pasión y muerte de Manuel Jesús", compuesta con tonadas religiosas alusivas a las conmemoración de Semana Santa, pero que eran una metáfora por las muertes y desapariciones ejecutadas por el gobierno militar. En los textos de dicha obra, se expresa el dolor de la Virgen (madre) ante la pérdida de su hijo, quien ha dado su vida por el pueblo pobre. Donoso, 2006: 176-177. 
donde la vecina y hasta en la fila para sacar agua. Pizarro logró revivir el lazo entre la cultura campesina y los pobladores, dando cuenta de cómo sobrevivían antiguas costumbres y creencias populares en la ciudad.

En ambas mujeres, entonces, se aprecia el interés por captar la cultura en su totalidad y encarnada en las personas. No hay en ellas definiciones teóricas ni apreciaciones sobre la vigencia de tal material o costumbre, o el origen de tal o cual danza, o discusiones de si se puede considerar folclórico o no un canto. Patricia Chavarría, por ejemplo, declaró que nunca estudió sobre teoría del folclore porque estaba "muy entretenida aprendiendo con las viejitas" 43 ; por lo tanto, su formación como investigadora fue autodidacta, pero en permanente diálogo con otros investigadores, tales como la misma Gabriela Pizarro, Osvaldo Jaque, incluso con Fidel Sepúlveda. En ese sentido, se crea una red de conocimientos no institucional sobre la cultura popular folclórica y sólo en reuniones privadas entre los conocidos y amigos circula este material. No hay un espacio común de discusión hasta que las Escuelas de Folclore se organizan en Concepción en 1984 44 . La dignificación del folclore para estas escuelas pasa por el reconocimiento de esta cultura tal como es:

"Nosotros [con Gabriela Pizarro y Osvaldo Jaque], tenemos muy claro que nuestra misión en este momento es de rescatar, estudiar, proyectar, dignificar y dejar testimonio de lo que es la cultura folclórica y mientras más dificultades tengamos, más responsabilidades sentimos frente a esto que hacemos por conciencia y por amor a nuestro pueblo. Más que motivaciones, existen muchas dificultades, no hay apoyos ni medios" ${ }^{\prime 5}$.

Por lo tanto, el folclore para estas investigadoras, más que un objeto de estudio, es una forma de vida que involucra lo material y lo espiritual, por lo tanto la recopilación de un canto o una danza no se hace sólo transcribiendo el texto y los sonidos, sino también el momento en que se canta, cómo lo hace la cantora, qué emociones involucra, qué siente ella al hacerlo, cuál es su rol dentro de una comunidad; es decir, captar el micromundo de los cultores. También vinculan el folclore a un grupo social: se estudia a los trabajadores, al campesinado, a la dueña de casa humilde, a los pobres. Con esta postura se distancian de la mirada "cosificadora" que entiende el folclore como elementos o hechos folclóricos. En 1983 Gabriela Pizarro declaró que "la gente está con sus vivencias y costumbres muy vivas, muy apegadas a las raíces" y que "el campesino es consciente, inteligente y por tanto siempre vamos a encontrar el folclore, eso no se termina, siempre está latente" 46 .

La recopilación también llevaba aparejada una tarea de difusión, la cual realizaban las mismas investigadoras interpretando el repertorio aprendido, junto con charlas explicativas. Pero también era común que incluyeran a las mismas cantoras y cultores en sus presentaciones. Ellas les hacían tomar conciencia a los cultores

\footnotetext{
${ }^{43}$ Donoso 2006: 176-177.

${ }^{44}$ De este hecho se da cuenta en Catalán y Torres 1983: 2.

${ }^{45}$ Boletín Informativo AM FOL CH I 1985: 12.

${ }^{46}$ Catalán y Torres 1983: 5 y 9.
} 
de la importancia de su trabajo y la necesidad de darlo a conocer. Por lo tanto, no se trataba de esconder la grabadora y captar la naturalidad del cantor o del poeta. En este tipo de investigación fue clave que el cultor/a quisiera participar y entregar su experiencia y legado.

Este trabajo tan cercano a los cultores las hizo distanciarse de las reproducciones artísticas del canto popular que tomaban los elementos del espectáculo, imitando la fórmula Bafona. El folclore que ellas estudiaban era justamente el folclore que "no vendía" y marcaron su distanciamiento con esa interpretación. Debieron crear espacios paralelos de difusión y de organización, distanciándose también, como hemos planteado, del concepto de lo folclórico, para nominar estas expresiones ahora como "cultura tradicional popular". Su interés, más que por los hechos, es por las personas que los viven, por eso no sirve su representación con luces y colores sobre un escenario. Con ese método se logra entretener al público pero no transmitir el sentimiento del pueblo al que se quiere representar.

“[Para los] medios de comunicación, folclore es lo que se vende. Darle cabida a nuestra cultura popular significa darle cabida a nuestro pueblo y eso es algo que no se va a dar en estos momentos, a pesar de que el pueblo está creando un testimonio de lo que está sucediendo y está sintiendo en forma acallada, llegado el momento es algo que va a aflorar, porque el pueblo está vivo y es él quien está escribiendo su propia historia" 47 .

Desde 1975, la creación de peñas folclóricas fue un espacio vital para la participación de los investigadores y artistas que fueron excluidos (o autoexcluidos) del circuito oficial. Estos lugares se constituyeron como espacios de encuentro con viejas lealtades artísticas y políticas, de reencuentro con nuevos modos de articular una resistencia cultural al gobierno militar, creando un circuito cultural alternativo que estuvo compuesto por agrupaciones culturales, algunos sellos discográficos, la productora N u estro Canto, la revista L a Bicicleta, eventos en el Teatro Caupolicán, destacando el trabajo realizado por Ricardo García y Nano Acevedo, quienes le dieron cabida a los conjuntos de proyección folclórica ${ }^{48}$.

Un segundo espacio usado por los folcloristas disidentes fue la Asociación Metropolitana de Folcloristas (AMFOLCHI), que nació en 1980 como una forma de distanciarse de la labor realizada por la Confederación Nacional de Conjuntos Folclóricos de Chile, organizadores del Festival de San Bernardo y que estaban participando de las políticas culturales del gobierno militar ${ }^{49}$. Fue presidida por investigadores y músicos, como la ya mencionada Gabriela Pizarro, Osvaldo Jaque, Alejandro Hermosilla y Lucy Casanova, durante los años 80.

AMFOLCHI nació como una forma de oposición y así se plantearon en esa trinchera desde los primeros años, discutiendo no sólo el apoyo a un gobierno

\footnotetext{
${ }^{47}$ Boletín Informativo AM FOLCH I 1985: 17.

${ }^{48}$ Sobre las peñas ver González y Bravo 2006; sobre el circuito cultural alternativo, una buena referencia es el documento Rivera 1983.

${ }^{49}$ Entre los folclorista que dirigieron esta Asociación durante los años 80 están Osvaldo Jaque, Alejandro Hermosilla, Lucy Casanova y Gabriela Pizarro.
} 
autoritario, sino también el tipo de folclore artístico que se estaba difundiendo desde las oficinas de gobierno: el folclore-espectáculo.

A través de la revista El A rado, esta agrupación gremial dio a conocer su postura con respecto a dichas políticas culturales, criticando el carácter del Festival de Viña del Mar, el cual "constituye un elemento distorsionador de nuestra cultura" ${ }^{50}$. Para ellos, la competencia folclórica no representaba el profundo sentido del folclore, el que "es vida y es la expresión cotidiana (no reducida a cantos y al baile) de los sectores más humildes de nuestros pueblos, y que por cierto no se ven reflejados en los medios de comunicación" 51 .

Junto con el discurso emitido a través de su órgano de difusión, intentaron realizar cursos y talleres de formación para sus asociados, para potenciar su creación artística y su trabajo de proyección del folclore y ejecutar en el trabajo los planteamientos de la Asociación. Una de las dificultades que visualizaba AMFOLCHI era la carencia de un modelo de proyección folclórica que fuera coincidente con su forma de comprender el folclore. Los modelos difundidos por los medios de comunicación correspondían al modelo oficial, que implicaba una "estilización" y "depuración" de la cultura tradicional, lejana de la real labor que, según la agrupación, debía tener la proyección folclórica:

"El folclore es mucho más que cantar y danzar, es una forma de vida del pueblo... Cuando en nuestra asociación decimos que estamos reunidos bajo su alero por el compromiso de rescatar y defender nuestro folclore, debemos asumir esa responsabilidad y meditar sobre lo que significa esa palabra. Una proyección sin ese compromiso de una verdadera defensa de los valores culturales es un trabajo artístico paternalista, cómodo y flojo y carece de validez porque le falta la relación del hombre con su medio ambiente... Un trabajador de la cultura que no comprende y plantea al hombre folclórico en todo su universo será sin duda descalificado por los propios cultores. El artista no sólo debe estar en las fiestas del pueblo, sino también en sus luchas por conseguir sus derechos" $" 52$.

Creemos que el papel de AMFOLCHI fue proponer una fórmula de organización autónoma con respecto a las instituciones culturales oficiales, manteniendo una oposición social y política al gobierno militar y siendo parte de la recuperación de la responsabilidad social que el artista de izquierda tenía con el arte popular, relación que fue profundamente desarrollada en la década de 1960 hasta el golpe de Estado.

En suma, las interpretaciones brevemente expuestas en el tercer punto corresponden a una vertiente discursiva que comprende el folclore como una parte de la cultura popular. El origen de esta mirada lo hemos datado en la Sociedad del Folklore Chileno, y principalmente en la propuesta de Rodolfo Lenz, teniendo sucesivos exponentes desde 1920. Creemos que Juan Uribe-Echevarría y Fidel Sepúlveda retoman esta línea desde lo académico, y Gabriela Pizarrojunto a Patricia

${ }^{50}$ El Arado 1988: 24.

51El Arado 1985: 3.

52El Arado 1985: 3. 
Chavarría lo hacen desde lo artístico, concibiendo el estudio de lo folclórico como una búsqueda de las experiencias humanas que dan vida a las manifestaciones provenientes de una cultura tradicional.

No obstante, hemos planteado que durante el Régimen Militar se produjo la arremetida de las ópticas nacionalistas y del folclore como espectáculo, las que fueron creadas de manera sucesiva, desde la década de 1940 hasta constituirse como parte del discurso oficial en 1973. Los debates entre ambas grandes líneas interpretativas se fueron reproduciendo en diversos espacios: académico, artístico, de la industria cultural y en las políticas culturales de gobierno, llegando incluso a los debates en torno a la identidad nacional.

El discurso cultural que el gobierno de Pinochet acogió e incorporó aún se mantiene en las políticas estatales; aún se concibe que forman parte de la identidad nacional las manifestaciones artísticas de espectáculo y ciertos valores y esencias que es necesario reproducir cada año durante las fiestas del 18 de septiembre. Por lo tanto, la "batalla del folclore" por recuperar su matriz popular y vivencial sigue dándose, intentando mantener un circuito alternativo de difusión, de penetrar en los espacios universitarios y en la gestión de proyectos de investigación y proyección locales, de archivos sobre cultura tradicional, tratando de ser parte del patrimonio cultural, ubicándose en un marco que ya abandonó el concepto de folclore, pero que una y otra vez alude y reivindica, a veces sin ser consciente de ello, la defensa que Rodolfo Lenz realizó en 1909.

\section{BIBLIOGRAFIA}

Libros y artícu los

Alegría, Julio

1981 "La cueca urbana o cueca chilenera", A raucaria de Chile, No 14, pp. 125-135.

CARdemil, Alberto

2000 El huaso chileno. Santiago: Andrés Bello.

Catalán, Carlos y Rodrigo Torres (eds.)

1983 Cultura y recolección folclórica en Chile. Santiago: CENECA.

Conjunto Millaray

1971 La ramada, Serie El FolcloredeChile, vol. XXVI, disco LP, Santiago: Sello Emi-Odeón.

Dannemann, Manuel

1960 "Los estudios folclóricos en nuestros ciento cincuenta años de vida independiente", A nales de la Universidad de Chile, $\mathrm{N}^{\circ}$ 120, pp. 203-217.

1975 "Situación actual de la música folklórica chilena. 'Según el Atlas del Folklore de Chile", RM Ch, XXIX/ 131 (julio-septiembre), pp. 38-86.

1978 "Plan multinacional de relevamiento musicológico y folklórico. Misión Chile 1977", RM Ch, XXXII/ Nº141 (enero-marzo), pp. 17-41.

1998 Enciclopedia de folclore deChile. Santiago: Editorial Universitaria. 
DONOSO, KAREN

2006 La batalla del folclore: los conflictos por la representación de la cultura popular en Chile. Tesis para obtener el grado de Licenciatura en Historia. Santiago: Universidad de Santiago de Chile.

2008 “Canción huasa o canto nuevo? La identidad chilena en la visión de izquierdas y derechas, 1973-1989", en Verónica Valdivia (et al.), Su revolución contra nuestra re volución. La pugna marxista-gremialista en los ochenta. Volumen 2. Santiago: LOM Ediciones, pp. 231-290.

Flores, Eliodoro

1911 “Adivinanzas corrientes en Chile”, Anales de la Universidad de Chile, tomo 128, enero-junio, pp. 765-844.

Garretón, Manuel Antonio

1995 Por la fuerza sin la razón. A nálisis y textos de los bandos dela dictadura militar. Santiago: LOM Ediciones.

González, Cristián y Gabriela Bravo

2006 Ecos del tiempo subterráneo: las peñas en Santiago durante el Régimen Militar. 19731983. Tesis para obtener el grado de Licenciatura en Periodismo. Santiago: Universidad de Santiago de Chile.

Hobsbawn, Eric y Terence Rangers (eds.)

2002 La invención dela tradición. Capítulo 7. Barcelona: Ed. Crítica.

LaRgo Farías, RenÉ

1977 La Nueva Canción Chilena, Cuadernos Casa de Chile, № 9.

LATORRE, Mariano

1969 Chile país de rincones. Santiago: Zig-Zag.

LEÓN Echaíz, RENÉ

1955 Interpretación histórica del huaso chileno. Santiago: Universitaria.

Rengifo, Eugenio y Catalina Rengifo

2008 Los Cuatro H uasos. Alma dela tradición y el de tiempo. Santiago: Catalonia-SCD.

RIVERA, ANNY

1983 Transformaciones culturales y movimiento artístico en el orden autoritario. Chile 19731982. Santiago: CENECA.

SEPÚlVEDA, Fidel

1983 "Notas para una estética del folclore", Aisthesis, N 15, pp. 13-18.

1985 "Folclore y cultura regional. Una aproximación estética”, A isthesis, Nº 18, pp. 45-54.

Stabili, María Rosaria

2003 El sentimiento aristocrático. Elites chilenas mirándose frente al espejo 1860-1960. Capítulo 3, "La tierra". Santiago: Andrés Bello.

TORRES, RODRIGO

2003 "El arte de cuequear: identidad y memoria del arrabal chileno", en Sonia Montecino (comp.), Revisitan do Chile: identidades, mitos e historias. Santiago: Cuadernos Bicentenario Presidencia de la República, $N^{\circ} 1$. Arturo Infante (ed.). Ver http:/ / www.cuecachilena.cl/RemoliendoTorres.html. 
URIBE-ECheVARRÍA, JUAN

1973 "La glosa política en la poesía popular del siglo XIX", Boletín de la Academia de H istoria, $\mathrm{N}^{\circ} 87$, pp. 94-144.

1974 Tipos y cuadros de costumbre en la poesía popular del siglo XIX. Santiago: Editorial Pineda.

Valencia Avaria, Luis

1974 Los símbolos patrios. Santiago: Editora Nacional Gabriela Mistral.

Vega, Carlos

1959 La ciencia del folklore. Buenos Aires: Editorial Nova.

Vial, Gonzalo

1984 "Decadencia, consensos y unidad nacional", Dimensión histórica de Chile, $\mathrm{N}^{\circ} 1$, pp. 140-146.

Periódicos y revistas

1911 “Una vergüenza”, El Diario llustrado, 23 de agosto, p. 1.

1911 “La pornografía en los Anales de la Universidad”, La Unión, 23 de agosto, p. 1.

1911 “Adivinanzas corrientes en Chile”, El M ercurio, 25 de agosto, p. 1.

1966 "El hombre... intimidad clandestina", Ercilla, № 1641, 16 de noviembre, p. 29.

1974 "Cinco minutos en Alemania”, Ercilla, № 2024, 15 de mayo, p. 43.

1974 “Los Quincheros, aún en el exterior fueron agredidos", La Segunda, 11 de septiembre, p. 44.

1976 “Los Quincheros hacen historia”, QuéPasa, № 254, 4 de marzo, p. 58.

1985 QuéPasa, No 728, 21 al 17 de marzo, p. 44.

1985 "Editorial”, El Arado, № 6, mayo, p. 3.

1985 "El artista: un comunicador social”, El Arado, N 7, agosto, p. 3.

1985 "Patricia Chavarría. El folclore como forma de vida", Boletín Informativo AM FO L CH I, $\mathrm{N}^{\circ} 7$, agosto, p. 12.

1988 El Arado, No 13, mayo, p. 24.

1989 Revista Proyección de la Cultura, Secretaría de Relaciones Culturales, N 15, septiembre, p. 17.

1992 “Gabriela Pizarro en la historia de nuestro canto. II", ChileRíey Canta, N 3, mayojunio, p. 21.

Documentos

1911 Carta enviada por Domingo Amunátegui a Rodolfo Lenz, 22 de agosto. Archivo Rodolfo Lenz, Universidad Metropolitana de Ciencias de la Educación (UMCE).

1974 "Declaración de principios del Gobierno de Chile", Santiago: s/e, p. 11.

1975 "Política Cultural del Gobierno de Chile". Santiago: Asesoría General de la Junta de Gobierno. 
1975 Carta de Héctor Pavez a René Largo Farías, París, 3 de julio.

1987 Diez Años deExtensión Cultural. Santiago: Ministerio de Educación.

2000 Oficio $N^{\circ}$ 4878, de la Cámara de Diputados al Ministerio de Educación. 15 de marzo. 